\title{
Jealousy and Monetary Policy
}

\author{
Juha Tervala* \\ University of Helsinki and HECER
}

University of Helsinki, Department of Economics

Discussion Paper No. 627:2006

ISBN 978-952-10-2774-1, ISSN 1459-3696

January 10, 2007

\begin{abstract}
The aim of this paper is to examine the implications of jealousy for the welfare effects of monetary policy. Jealousy implies that consumption is like pollution: overconsumption may occur because households do not internalize the costs of their consumption on others. This externality opens the door for a beneficial monetary policy intervention. We show that the welfare effects of monetary policy depend on the relative strength of the consumption externality and the monopolistic distortion. If households are "too jealous", a rise in the money supply reduces welfare by increasing consumption that is already inefficiently high.
\end{abstract}

Keywords: Monetary policy, jealousy, consumption externality

JEL classification: E50, E60

*Postal address: Department of Economics, P.O. Box 17, FI-00014 University of Helsinki. E-mail address: juha.tervala@helsinki.fi

Financial support from the Yrjö Jahnsson Foundation is gratefully acknowledged. I thank Pertti Haaparanta, Kari Heimonen, Tapio Palokangas, Otto Toivanen and Mika Widgrén for comments. 


\section{Introduction}

The purpose of this paper is to analyze the implications of jealousy for monetary policy. Jealousy and the desire to "keep up with the Joneses" imply that consumption is like pollution: overconsumption may occur because households do not internalize the costs of their consumption on others. A household which increases its consumption does not take into account its effect on the aggregate desire by other households to "keep up". On the other hand, in imperfectly competitive economies production tends to fall below the social optimum. Jealousy and monopolistic competition create distortions that can be potentially corrected by a monetary policy intervention.

The introduction of jealousy into a standard model allows for identifying additional features that govern the welfare effects of monetary policy. The implications of jealousy for asset-pricing and optimal taxation have caught some attention; ${ }^{1}$ but its implications for monetary policy have attracted little attention. In a rare paper, Pierdzioch (2003) analyses the implications of jealousy for the welfare effects of monetary policy, using of a two-country model. He finds that, if households are jealous, a rise in the money supply can be a beggar-thyself policy. However, he did not provide a clear result when monetary policy is welfare-decreasing. On the other hand, virtually all other monetary policy models have shown that a rise in the money supply always increases welfare. The intuition behind this result is that, under monopolistic competition, an increase in output is welfare-improving because the level of production is inefficiently low.

We show in this paper that, in the closed economy, the welfare effects of monetary policy depend on the relative strength of the consumption externality caused by and the monopolistic distortion. If the former dominates, a rise in the money supply is welfare-reducing because an increase in output is not desirable. If households are "too jealous", the economy suffers from overproduction. Therefore, a rise in the money supply is not welfare-improving because it increases consumption that is already inefficiently high.

The rest of the paper is organized as follows. In Section 2, we present the model. In Section 3, we examine the implications of jealousy for the welfare effects of monetary policy. Section 4 concludes the paper.

\footnotetext{
${ }^{1}$ Important contributions include, but are not limited to, Dupor and Liu (2003), Gali (1994), Guo (2005) and Ljungqvist and Uhlig (2000).
} 


\section{The Model}

\subsection{Preferences and Market Structure}

In this section, we develop a simple model to analyze the implication of jealousy. The economy is inhabited by a continuum of households. The size of the economy is normalized to unity. The households are indexed by $z \in[0,1]$. The economy is monopolistically competitive and each household produces a single differentiated commodity. For simplicity, the model abstracts capital formation and thus labour is the only factor of production.

The utility function of representative household $i$ is

$$
U^{i}=\log \left(C^{i}-\alpha C^{A}\right)+\chi \log \left(\frac{M^{i}}{P}\right)-\frac{\kappa}{2} y(i)^{2} .
$$

The variable $C^{i}$ is a CES basket of all varieties consumed by household $i$

$$
C^{i}=\left[\int_{0}^{1} c^{i}(z)^{\frac{\theta-1}{\theta}} d z\right]^{\frac{\theta}{\theta-1}},
$$

where $c^{i}(z)$ is consumption of commodity $z$ by household $i$ and $\theta(>1)$ is the elasticity of substitution between varieties. In the utility function, $C^{A}$ is average consumption goods across all households. The parameter $\alpha$ $(0<\alpha<1)$ captures the importance of average consumption, as we shall explain in a moment. $\chi$ is a positive parameter, $M^{i}$ money holdings and $P$ denotes the consumer price index

$$
P=\left[\int_{0}^{1} p(z)^{1-\theta} d z\right]^{\frac{1}{1-\theta}},
$$

where the price of commodity $z$ is denoted by $p(z)$. In equation $(1), y(i)$ stands for the output of commodity $i$ and $\kappa$ is a parameter that captures the disutility of production.

The parameter $\alpha$ captures the notion of jealousy. The utility function implies that

$$
\frac{\partial U}{\partial C^{A}}=\frac{-\alpha}{C^{i}-\alpha C^{A}}<0 .
$$

Hence, an increase in average consumption lowers the representative household's utility level and increases the household's marginal utility of additional consumption. In a symmetric equilibrium where the representative household consumes average consumption $\left(C^{i}=C^{A}\right)$

$$
\frac{\partial U}{\partial C^{i}}=\frac{1}{C^{i}}>0 \text {. }
$$


This equation implies that in case where every household's consumption increases in tandem, utility increases.

Let us define the marginal rate of substitution between leisure and consumption to be

$$
M R S_{L C}=\frac{\partial U / \partial y(i)}{\partial U / \partial C^{i}}
$$

Thus in this model

$$
\frac{\partial M R S_{L C}}{\partial C^{A}}=\alpha y(i)>0,
$$

which implies that an increase in average consumption raises the marginal utility of the representative household's consumption relative to leisure. Again, following Gali (1994) and Dupor and Liu (2003), we refer to this property as "keeping up with the Joneses". If preferences exhibit the desire to keep up with the Joneses, the representative household derives greater utility from additional consumption relative to leisure when other households consume more. The keeping up with the Joneses effect thus creates a consumption externality because the households do not take into account the negative effect of their consumption on others. We can however state that the keeping up with the Joneses effect is a feature of jealousy. Henceforth, we only talk of jealousy.

The budget constraint of the representative household is

$$
M^{i}+P C^{i}=M_{0}^{i}+P T+y(i) p(i),
$$

where $M_{0}^{i}$ is the initial money holdings and $T$ is per capita transfers from the government. The government repays all revenues from money creation to the households by transfer payments. The government budget constraint, expressed in per capita terms, is given by

$$
0=T+\frac{M-M_{0}}{P} \text {. }
$$

\subsection{Optimality Conditions}

The representative household maximizes the utility function (1) subject to the budget constraint (2), taking into account that it faces the downwardsloping demand curve

$$
y(i)=\left[\frac{p(i)}{P}\right]^{-\theta} C^{A D} .
$$

In this equation, $C^{A D}$ denotes aggregate demand for the representative commodity $i$. The representative household solves a maximization problem, 
choosing the level of consumption, money holdings and output that maximizes utility. The optimality conditions are

$$
\begin{gathered}
\chi\left(\frac{M^{i}}{P}\right)^{-1}=\frac{1}{C^{i}-\alpha C^{A}} \\
y(i)^{\frac{\theta+1}{\theta}}=\frac{(\theta-1)}{\theta \kappa}\left(C^{A D}\right)^{\frac{1}{\theta}}\left(C^{i}-\alpha C^{A}\right)^{-1} .
\end{gathered}
$$

Equation (3) shows the demand for money, households equate the marginal utility from holding money to the opportunity cost of acquiring it. Equation (4) is the labour-leisure trade-off condition. Households equate the marginal disutility of producing an extra unit of output to the marginal utility from consuming the added revenue that the extra unit of output brings.

\section{Jealousy and Monetary Policy}

\subsection{A Symmetric Steady State}

Later in this paper, we analyze the dynamic response of the economy to a rise in the money supply. To do this, we need a well-specified steady state around which we log-linearize the model. As we show, it turns out that the steady state level of output is crucial to the main result of this paper.

Consider, for simplicity, a symmetric equilibrium where

$$
\bar{y}_{0}(i)=\bar{C}_{0}^{A D}=\bar{C}_{0}^{i}=\bar{C}_{0}^{A},
$$

where 0 subscripts on barred variables denote the initial symmetric steady state. The preceding equation shows that we consider a symmetric equilibrium where the representative household consumes average consumption. In this case the first-order condition governing the optimal choice of output, equation (4), implies that in equilibrium

$$
\bar{y}_{0}(i)=\left[\frac{(\theta-1)}{\theta \kappa(1-\alpha)}\right]^{\frac{1}{2}} .
$$

A social planner would internalize the consumption externality by setting $C^{i}=C^{A D}$ and maximize the utility of consumption net of the costs of forgone leisure

$$
\max _{y}\left[\log (1-\alpha) y-\frac{\kappa}{2} y^{2}\right]
$$


The solution is given by

$$
\bar{y}_{0}^{S P}=\left(\frac{1}{\kappa}\right)^{\frac{1}{2}} .
$$

The comparison between equations (5) and (6) shows that two factors induce that, in the decentralized equilibrium, the output level can differ from the social optimum. First, in the decentralized equilibrium the marginal value of an additional unit of consumption exceeds the cost of forgone leisure. Thus monopolistic competition induces a distortion which magnitude is determined by the term $(\theta-1) / \theta$. Second, under keeping up with the Joneses, a household derives greater utility from additional consumption relative leisure when other households consumer more. Jealousy, therefore, tends to raise output. The relative magnitudes of these distortions determine whether the level of output exceeds the social optimum.

The comparison between (5) and (6) implies that

$$
\begin{aligned}
& \bar{y}_{0}^{S P}<\bar{y}_{0}(i), \text { if } \alpha>\frac{1}{\theta}, \\
& \bar{y}_{0}^{S P}>\bar{y}_{0}(i), \text { if } \alpha<\frac{1}{\theta} .
\end{aligned}
$$

According to the preceding equations, the consumption externality caused by jealousy can more than offset the negative effect caused by monopolistic competition. In this case, equilibrium output (consumption) is inefficiently high. On the other hand, if the households are only little jealous, the socially optimal output level exceeds the output level realized in the decentralized equilibrium. Therefore, we can conclude that jealousy is not necessarily a vice - on the contrary - jealousy can a virtue. Moderate jealousy can partly offset the imperfect competition distortion by increasing output closer to the social optimum without causing overconsumption. Hence, jealousy does not necessarily imply equilibrium overconsumption unlike Dupor and Liu concluded $(2003,427)$.

\subsection{The Welfare Effects of Monetary Policy}

The next step is to study the implications of jealousy for monetary policy. To do this, we analyze a log-linear version of the model and consider an unanticipated rise in the money supply. Assume that all prices are fixed and output is demand-determined. The log-linearized version of equation (3) implies that $\hat{M}=\hat{C}$, where the percentage deviations from the initial steady state are denoted by hats. The parameter $\alpha$ does not affect the loglinear version of the model. Thus jealousy does not affect the response of 
the economy to a rise in the money supply. On the other hand, jealousy has notable implications for economic welfare.

Ignoring the welfare effects of real balances, total differentiation of the utility function yields to

$$
d U^{i}=\hat{C}-\kappa \bar{y}_{0}^{2} \hat{C} .
$$

Using of equation (5), which gives initial steady-state output, the preceding equation becomes

$$
d U^{i}=\left[1-\frac{(\theta-1)}{\theta(1-\alpha)}\right] \hat{M} .
$$

Hence, a rise in the money supply is welfare-decreasing if

$$
\alpha>\frac{1}{\theta}
$$

Recalling equation (7), we can conclude that a rise in the money supply decreases welfare if the level of output exceeds the socially optimal level of output. The intuition behind this result is the following. A rise in the money supply increases demand. Since the initial level of output is already inefficiently high, a rise in the money supply only worsens the overconsumption problem. Thus a rise in the money supply is not desirable and it decreases welfare. On the other hand, a rise in the money supply increases welfare if steady-state output is inefficiently low. In this case, a rise in the money supply increases output that is inefficiently low and consequently increases welfare.

Virtually all monetary policy models have shown that a rise in the money supply always increases welfare. The intuition behind this result is straightforward. Under monopolistic competition, an increase in output increases welfare because the level of production is inefficiently low. On the other hand, Pierdzioch (2003) finds that a rise in the money supply can be welfarereducing if households are jealous. In his model, a rise in the money supply has an effect on welfare by affecting the terms of trade and the level of output. However, it is not completely clear when a rise in the money supply is a beggar-thyself policy. In this paper it is shown that, in the closed economy, the conditions under which a rise in the money supply is welfare-decreasing are transparent. If the closed economy suffers from overconsumption caused by jealousy, then a rise in the money supply is welfare-decreasing. 


\section{Conclusions}

Jealousy implies that consumption is like pollution: overconsumption may occur because households do not internalize the costs of their consumption on others. This externality opens the door for a beneficial monetary policy intervention. We show that jealousy is a key feature in governing the welfare effects of monetary policy. In contrast to virtually all monetary policy models, we show that a rise in the money supply can be welfare-decreasing. The intuition behind this result is clear. If households are "too jealous", the economy suffers from overconsumption and a rise in the money supply worsens the overconsumption problem. 


\section{References}

[1] DUPOR, B. - LIU, W-F. (2003): Jealousy and Equilibrium Overconsumption. American Economic Review 93, 423-428.

[2] GALI, J. (1994): Keeping Up with the Joneses: Consumption Externalities, Portfolio Choice and Asset Pricing. Journal of Money, Credit and Banking 26, 1-8.

[3] GUO, J-T. (2005): Tax Policy Under Keeping up with the Joneses and Imperfect Competition. Annals of Economics and Finance 6, 25-36.

[4] LJUNGQViST, L. - UHLIG, H. (2000): Tax Policy and Aggregate Demand Management Under Catching Up with the Joneses. American Economic Review 90, 356-366.

[5] OBSTFELD, M. - ROGOFF, K. (2000): New Directions for Stochastic Open Economy Models. Journal of International Economics 50, 117-53.

[6] PIERDZIOCH, C. (2003): Keeping Up with the Joneses: Implications for the Welfare Effects of Monetary Policy in Open Economies. Review of Economics / Jahrbuch für Wirtschaftswissenschaften 54, 167-177.

[7] WOODFORD, M. (2003): Interest and Prices: Foundations of a Theory of Monetary Policy. Princeton University Press: Princeton. 